\title{
Packing of a Splenic Artery Aneurysm Using a Novel Hydrogel-Coated Coil
}

\author{
1) Division of Endovascular Treatment, Department of Radiology, Japanese Red Cross Medical Center, Japan
}

Akinori Harada $^{1)}$, Yosuke Nozawa ${ }^{1)}$, Tetsuhisa Yamada ${ }^{1)}$, Jun-ichi Nishimura ${ }^{1)}$

\begin{abstract}
We report our initial experience with embolization of a splenic artery aneurysm in a woman in her 50s using the combination of large-diameter, hydrogel-coated detachable coils and a large-bore, high-flow microcatheter. The 20-mm diameter splenic artery aneurysm was packed densely with 10 hydrogel-coated coils, and the volume embolization ratio after full hydrogel expansion was $50.7 \%$, a strikingly high value. Excellent occlusion was achieved with a small number of hydrogel-coated coils, which yield high volumes. This procedure can reduce the need for retreatment.
\end{abstract}

Key words: Hydrogel-coated coil, Splenic artery aneurysm, Coil embolization, Azur35

(Interventional Radiology ; 4: 43-47)

\section{Introduction}

Endovascular treatment of visceral artery aneurysms is associated with good outcomes and has increasingly become a first-line treatment option [1-6]. Coil packing is an efficient approach for treatment of saccular aneurysms, although a high number of coils are needed for large aneurysms, which can lead to medical issues and increased cost. Hydrogelcoated coils increase in volume as the hydrogel expands after coil placement; therefore, fewer hydrogel-coated coils can be used for packing large aneurysms.

The Azur ${ }^{\circledR}$ and Azur $C X^{\circledR}$ are hydrogel-coated coils in the Azur $^{\circledR}$ series (Terumo, Tokyo, Japan), with each available in diameters of 0.018 and 0.035 inches. In the Azur series, the Azur35 has the largest diameter, and has been available in Japan since 2018. Both the Azur ${ }^{\circledR}$ and Azur CX ${ }^{\circledR}$ fill gaps between the platinum core coils through expansion of the hydrogel. The Azur ${ }^{\circledR}$ is coated with a hydrogel on the outside of the platinum core coil, and the coil diameter increases with expansion of the hydrogel. In contrast, the Azur $\mathrm{CX}^{\circledR}$ has a hydrogel coating inside the platinum core coil. Since the hydrogel in the Azur $\mathrm{CX}^{\circledR}$ fills gaps in the pri- mary coil, the coil diameter does not change after hydrogel expansion. Another distinction between the 2 hydrogelcoated coils is the shape of the secondary coil: the Azur ${ }^{\circledR}$ has a helical shape, while the Azur $\mathrm{CX}^{\circledR}$ has a complex 3dimensional shape. These characteristics are shown in Table 1.

This report describes our initial experience with successful packing of a splenic artery aneurysm (SAA) using Azur series coils. We mainly used the 0.035 -inch Azur $\mathrm{CX} 35^{\circledR}$ and Azur $35^{\circledR}$ coils. The choice of large-volume coils enabled use of fewer coils in this case.

\section{Case Report}

Ultrasonography as part of a routine medical checkup revealed a round pulsatile lesion with a diameter of $20 \mathrm{~mm}$ just above the pancreatic tail in a woman in her 50s with no relevant symptoms or medical history. Enhanced computed tomography (CT) revealed an SAA with a diameter of 20 mm (Fig. 1). Transcatheter therapy was chosen to treat the SAA. We planned intra-aneurysmal coil packing using hydrogel-coated detachable coils to achieve embolization with a smaller number of coils. 
Table 1. Characteristics of Azur ${ }^{\circledR}$ series hydrogel-coated coils

The lineup of Azur series

\begin{tabular}{|c|c|c|c|c|c|c|}
\hline \multirow{2}{*}{ Coil lineup } & \multirow{2}{*}{ hydrogel expansion } & \multicolumn{2}{|c|}{ primary diameter(inch) } & \multirow{2}{*}{$\begin{array}{c}\text { secondary } \\
\text { diameter(mm) }\end{array}$} & \multirow{2}{*}{ length $(\mathrm{cm})$} & \multirow{2}{*}{ loop shape } \\
\hline & & bare plutinum coil & after expansion & & & \\
\hline AzurCX18 & inside of coil & $0.0145 \sim 0.0150$ & $0.0145 \sim 0.0150$ & $4 \sim 20$ & $13 \sim 40$ & complex \\
\hline AzurCX35 & inside of coil & 0.0290 & 0.0290 & $4 \sim 20$ & 7 39 & complex \\
\hline Azur18 & outside of coil & 0.0145 & 0.0320 & 2 20 & $5 \sim 30$ & helical \\
\hline Azur35 & outside of coil & 0.0310 & 0.0480 & $3 \sim 20$ & $2 \sim 30$ & helical \\
\hline
\end{tabular}

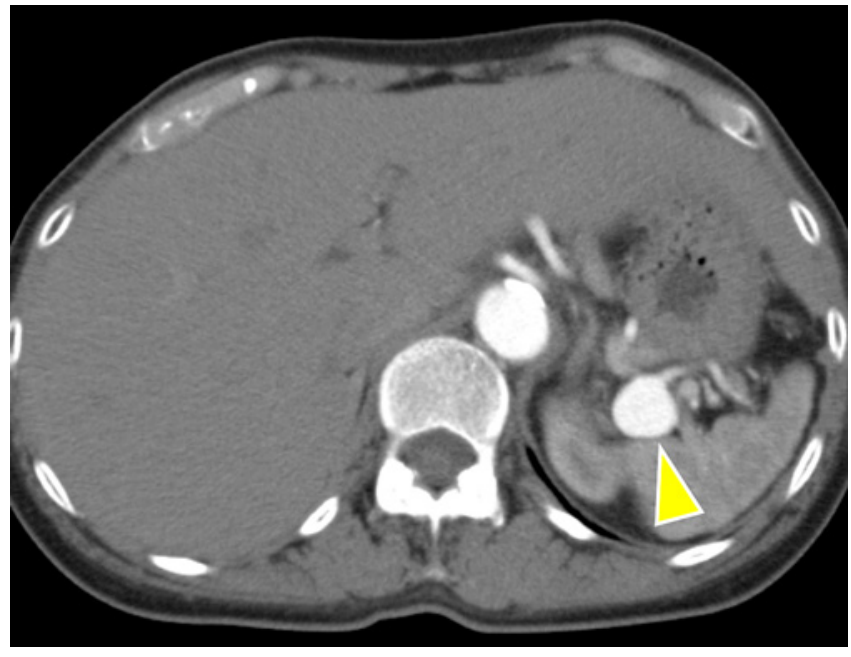

Figure 1. Enhanced computed tomography showing a 20mm diameter, splenic artery aneurysm (arrowhead).

\section{Embolization}

Two shepherd's hook-type 4.5-F guiding sheaths (Parent Plus 45, SHC; Medikit, Tokyo, Japan) were inserted sequentially into the bilateral femoral arteries and placed in the celiac artery. One guiding sheath was used for coiling, and the other sheath was used to advance a balloon catheter to preserve the splenic artery trunk. The presence of the SAA with a diameter of $20 \mathrm{~mm}$ was confirmed with celiac arteriography (Fig. 2). A 2.0-F microcatheter (Sniper2- $\mu 7$; Terumo Clinical Supply, Gifu, Japan) was advanced to the peripheral side of the splenic artery using a 0.014-inch guidewire (Cruise; Asahi Intecc, Aichi, Japan). The microcatheter was exchanged for a $4 \mathrm{~mm} \times 40 \mathrm{~mm}$ percutaneous transluminal angioplasty balloon catheter (Sterling; Boston Scientific Japan, Tokyo, Japan). Through another sheath, a 3.4-F high-flow microcatheter (Tactics; Technocrat Corporation, Aichi, Japan) was indwelled in the aneurysm using a 0.025-inch guidewire (Radifocus; Terumo) (Fig. 3), and coil packing was performed. The balloon catheter was inflated during coil embolization to prevent coil protrusion. The SAA was packed with a total of 10 hydrogel-coated detachable coils. Two $20 \mathrm{~mm} \times 39 \mathrm{~cm}$ Azur CX35 ${ }^{\circledR}$ coils were initially placed for framing. Then, 4 Azur $35^{\circledR}$ coils $(12 \mathrm{~mm}$ $\times 30 \mathrm{~cm}$ and $6 \mathrm{~mm} \times 20 \mathrm{~cm}, 2$ each) were placed into the

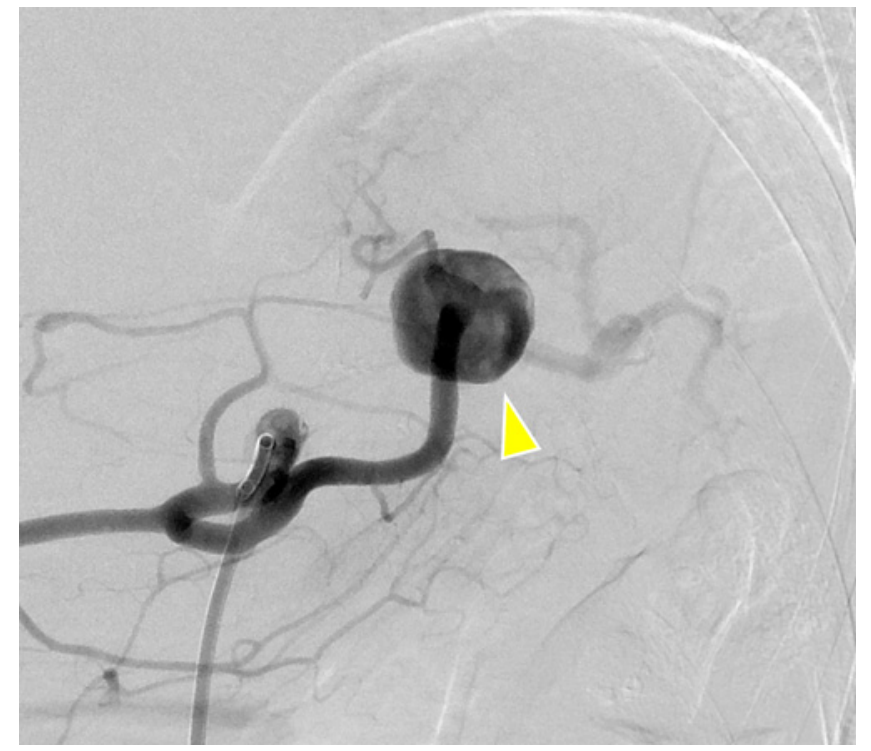

Figure 2. Celiac arteriography showing a large, saccular splenic artery aneurysm (arrowhead).

aneurysm for filling. Finally, 4 Azur $18^{\circledR}$ coils $(6 \mathrm{~mm} \times 20$ $\mathrm{cm}$, all) were used for filling and finishing. Postembolization arteriography confirmed successful occlusion of the SAA as well as patency of the splenic artery (Fig. 4, 5). No complications such as organ ischemia or pancreatitis occurred after the procedure. The patient has been followed as an outpatient, and ultrasound examination at 4 months after the procedure showed no blood flow into the aneurysm.

\section{Volume embolization ratio}

Aneurysm volume was calculated as a prolate spheroid: $(\mathrm{V}=4 / 3 \pi \times \mathrm{a} \times \mathrm{b} \times \mathrm{c})$, where $\mathrm{a}, \mathrm{b}$, and $\mathrm{c}$ were half the greatest diameter of the aneurysm in 3 perpendicular directions measured with contrast-enhanced CT. Coil volume was calculated as a cylinder: $(\mathrm{V}=2 \mathrm{r} \times \pi \times 1)$, where $\mathrm{r}$ was half the outer diameter of the coil and 1 was the length of the coil. The total volume of all coils was also calculated. The volume embolization ratio (VER) was calculated as follows:

$\operatorname{VER}(\%)=($ volume of coils/volume of aneurysm $) \times$ 100.

In the current patient, the SAA measured $20.0 \times 19.0 \times$ $19.0 \mathrm{~mm}$, with a volume of $3,780.4 \mathrm{~mm}^{3}$. Therefore, the 


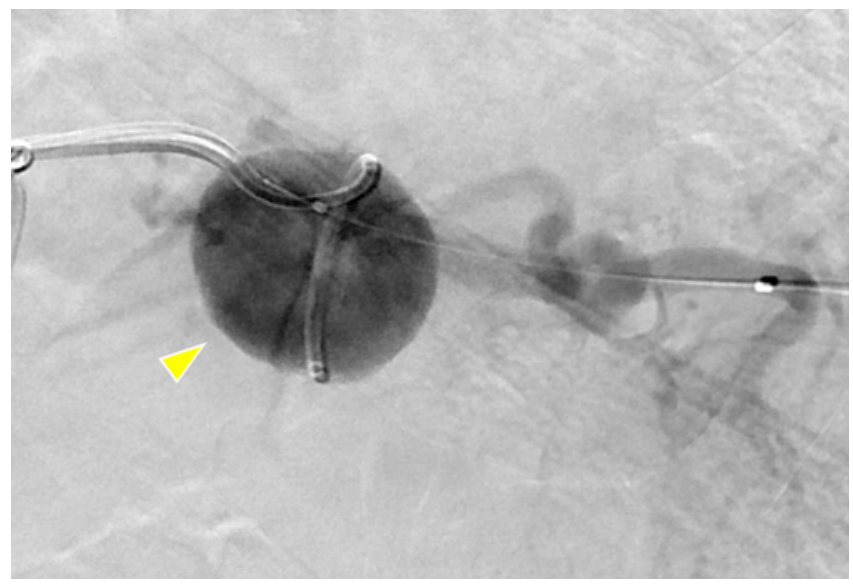

Figure 3. Angiography with a high-flow microcatheter (Tactics ${ }^{\circledR}$ ) placed inside the aneurysm (arrowhead).
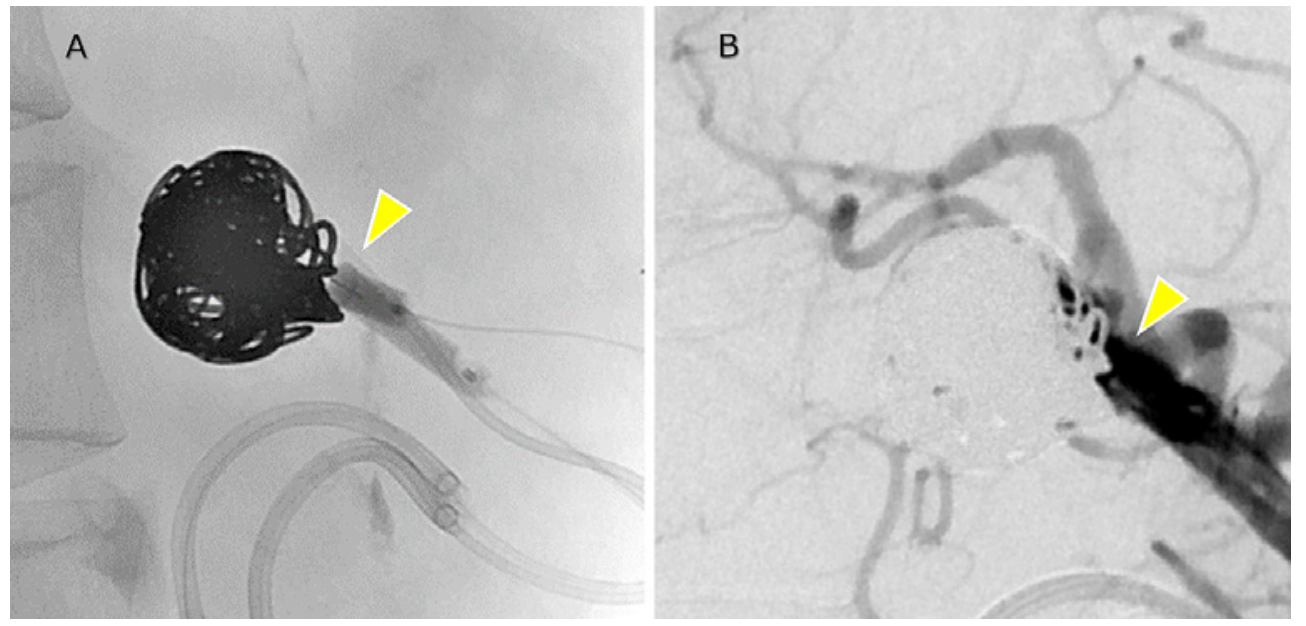

Figure 4. A: Lateral view of splenic artery aneurysm during coil packing demonstrates the relationship between the aneurysmal neck and parent artery, with temporary occlusion using a percutaneous transluminal angioplasty balloon (arrowhead). B: Lateral view of celiac arteriography during coil packing shows patency of the splenic artery trunk (arrowhead).
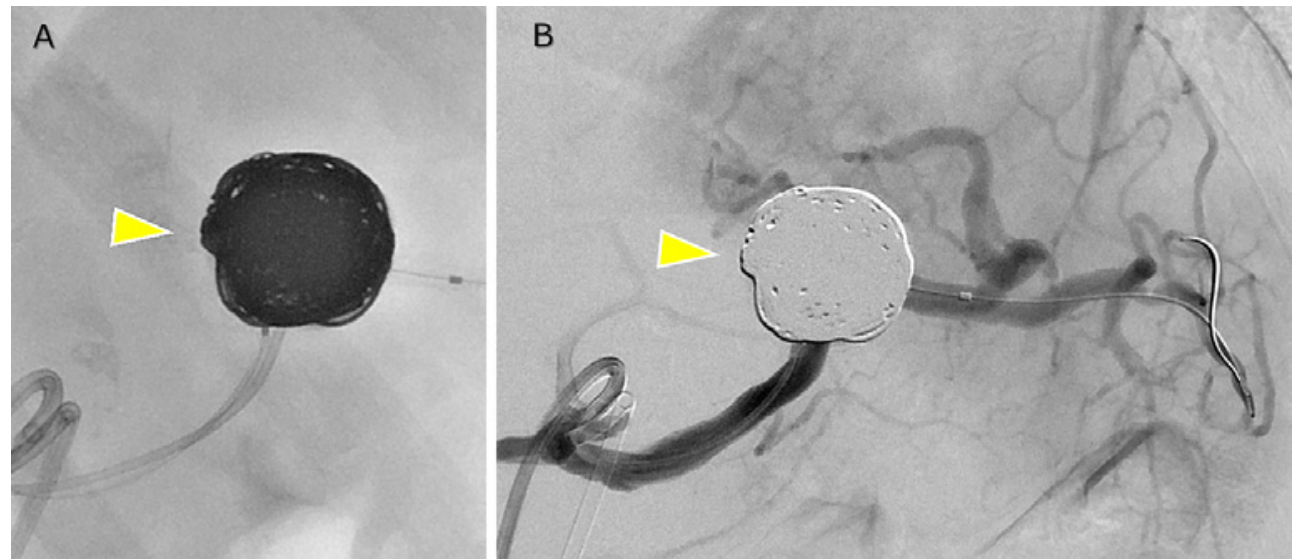

Figure 5. A: A total of $\mathbf{1 0}$ coils are densely packed in the splenic artery aneurysm (arrowhead). B: Celiac arteriography after coil packing shows disappearance of contrast medium flow into the aneurysm (arrowhead) and patency of the splenic artery trunk. 
to obtain a high VER in large-diameter or wide-necked aneurysms.

The Azur35 ${ }^{\circledR}$ is considered especially useful for large aneurysms. This is a detachable, 0.031-inch, platinum core coil covered with hydrogel, that can expand to 0.048 inches within approximately $20 \mathrm{~min}$ after contact of the hydrogel polymer with blood, providing approximately 4 times more filling volume compared with conventional, bare platinum, 0.035 -inch coils $[9,10]$. Therefore, vessel occlusion with the Azur $\left.^{(}\right)$series occurs through a volume- and space-occupying effect, not a thrombotic effect, which is more often observed with fibered coils $[11,12]$. In the Azur ${ }^{\circledR}$ series, the Azur35 ${ }^{\circledR}$ achieves the largest volume, and the high embolic effect reduces the number of coils used. In the current patient, about 40 20-cm-long, 0.018-inch coils would be required to achieve a VER of $24 \%$; this could not only lead to medical issues and increased cost but also increased procedure time and radiation exposure.

In the current case, we used Azur $\mathrm{CX} 35^{\circledR}$ coils with the same diameter as that of the aneurysm for initial framing for several reasons. First, the Azur $\mathrm{CX} 35^{\circledR}$ loop has a complex 3-dimensional shape that is suitable for framing. Second, since the outer diameter does not change after hydrogel expansion, contact with the vessel wall does not increase the pressure in the aneurysm. Following framing with the Azur CX35 ${ }^{\circledR}$, we used the Azur $35^{\circledR}$ to further increase coil volume. Since the hydrogel of the Azur $35^{\circledR}$ expands on the outside of the coil, the smallest secondary coil diameter of 12 $\mathrm{mm}$ was selected among the longest length of $30 \mathrm{~cm}$, to avoid overpressure in the aneurysm through hydrogel expansion. Next, the smallest secondary coil diameter of $6 \mathrm{~mm}$ was also chosen among the second longest $20 \mathrm{~cm}$ long coils. As the last coil, we selected the Azur $18^{\circledR}$ with a length of $20 \mathrm{~cm}$; this coil is much softer than a 0.035 -inch coil, enabling easy placement in the aneurysm. Among the soft, 0.018 -inch coils, we aimed at using a more voluminous coil. An approximate VER of $24 \%$ using platinum core coils alone was set as the goal of embolization. Toward the end, the catheter tip nearly slipped out from the aneurysm due to kickback, so we finished the procedure at that time.

Delivery of 0.035 -inch coils for aneurysm packing requires a large-bore, 4.0-F diagnostic or comparable catheter.

In the current case, the delivery catheter was easily and atraumatically introduced into the aneurysm using a Tactics ${ }^{\circledR}$ flexible high-flow microcatheter, with a 0.035 -inch inner lumen. An inner catheter as large as $2.5 \mathrm{~F}$ can be inserted into the lumen of the Tactics ${ }^{\circledR}$ microcatheter.

However, careful attention is required during coil packing, even with the combination of 0.035 -inch coils and a Tactics ${ }^{\circledR}$ microcatheter, because the use of large and stiff coils can cause early catheter kick-back and may increase the risk of aneurysm rupture during the procedure. In addition, the 0.035-inch coil has no alignment marker, making identification of the detachment point challenging. Since the Tactics ${ }^{\circledR}$ is a one-marker microcatheter, inserting an inner catheter with 2 markers into a Tactics ${ }^{\circledR}$ microcatheter when using a 0.018-inch coil might be considered as a safer coil packing approach.

There are several disadvantages associated with hydrogelcoated coils, especially the Azur $35^{\circledR}$ and Azur $18^{\circledR}$, in which the hydrogel expands outward. First, the repositioning time during coil indwelling is limited to $3 \mathrm{~min}$ [10]. Otherwise, the expansion of the hydrogel may cause the coil to stick in the catheter or become unremovable. In cases where a Tac$\operatorname{tics}^{\circledR}$ microcatheter is used in combination with the Azur35 ${ }^{\circledR}$, the repositioning time may be further shortened, because the Tactics $^{\circledR}$ microcatheter has a little smaller inner lumen than the common 4.0-F diagnostic catheter. Second, the hydrogel may not fully expand at the point where the coils overlap or where they come in contact with the vessel wall. Therefore, the volume of the coil after expansion of the hydrogel is only an estimate. Finally, if the coil unravels, the hydrogel might be damaged and become fragmented, and the pieces of the fragmented hydrogel pose a risk of distal migration.

\section{Conclusion}

We have reported our initial experience with the Azur35 ${ }^{\circledR}$ coil, which can achieve maximum volume and improvement in the filling rate with no dependence on thrombus formation. Use of the Azur $35^{\circledR}$ enables embolization with fewer coils, shortens the procedure time, reduces radiation exposure, and reduces medical expenses. Development of a Tactics $^{\circledR}$ microcatheter with 2 markers and a 0.035 -inch coil with an alignment marker should lead to technically easier procedures.

Conflict of interest: The authors have no conflicts of interest to report.

\section{References}

1. Etezadi V, Gandhi RT, Benenati JF, Rochon P, Gordon M, Benenati MJ, et al. Endovascular treatment of visceral and renal artery aneurysms. J Vasc Interv Radiol 2011; 22: 1246-1253.

2. Sessa C, Tinelli G, Porcu P, Aubert A, Thony F, Magne JL. Treatment of visceral artery aneurysms: description of a retrospective series of 42 aneurysms in 34 patients. Ann Vasc Surg 2004; 18: 695-703.

3. Ikeda O, Tamura Y, Nakasone Y, Iryou Y, Yamashita Y. Nonoperative management of unruptured visceral artery aneurysms: Treatment by transcatheter coil embolization. J Vasc Surg 2008; 47: 1212-1219.

4. Patel A, Weintraub JL, Nowakowski FS, Kim E, Fischman AM, Ellozy SH, et al. Single-center experience with elective transcatheter coil embolization of splenic artery aneurysms: technique and midterm follow-up. J Vasc Interv Radiol 2012; 23: 893-899.

5. Yamamoto S, Hirota S, Maeda H, Achiwa S, Arai K, Kobayashi $\mathrm{K}$, et al. Transcatheter coil embolization of splenic artery aneurysm. Cardiovasc Intervent Radiol 2008; 31: 527-534.

6. Yasumoto T, Osuga K, Yamamoto H, Ono Y, Masada M, Mikami $\mathrm{K}$, et al. Long-term outcomes of coil packing for visceral aneurysms: correlation between packing density and incidence of coil compaction or recanalization. J Vasc Interv Radiol 2013; 24 : 
1798-1807.

7. Uchiyama N, Kida S, Nomura M, Hasegawa M, Yamashima T, Yamashita J, et al. Significance of volume embolization ratio as a predictor of recanalization on endovascular treatment of cerebral aneurysms treated with Guglielmi detachable coils. Intervent Neuroradiol 2000; 6 Suppl 1: 59-63.

8. Tamatani S, Ito Y, Abe H, Koike T, Takeuchi S, Tanaka R. Evaluation of the stability of aneurysms after embolization using detachable coils: Correlation between stability of aneurysms and embolized volume of aneurysms. Am J Neuroradiol 2002; 23: 762767.

9. Ginat DT, Saad W, Kitanono T. Balloon-occluded retrograde transvenous obliteration of a gastrorenal shunt using hydrogel-coated coil embolization. Radiology Case Rep 2009; 4: 1-4.
10. Osuga K, Kishimoto K, Tanaka K, Nakamura M, Ono Y, Maeda $\mathrm{N}$, et al. Initial experience with use of hydrogel microcoils in embolization of pulmonary arteriovenous malformations. Springer Plus 2014; 3: 609.

11. Ferral H. Hydrogel-coated coils: product description and clinical applications. Semin Intervent Radiol 2015; 32: 343-348.

12. Fohlen A, Namur J, Ghegediban H, Laurent A, Wassef M, Pelage JP. Peripheral embolization using hydrogel-coated coils versus fibered coils: short-term results in an animal model. Cardiovasc Intervent Radiol 2018; 41: 305-312.

Interventional Radiology is an Open Access journal distributed under the Creative Commons Attribution-NonCommercial 4.0 International License. To view the details of this license, please visit (https://creativecommons.org/licenses/by$\mathrm{nc} / 4.0 /)$. 